\title{
ACCURACY OF PREGNANCY DIAGNOSIS WITH COMMERCIALLY AVAILABLE PROGESTERONE KIT IN DAIRY COWS
}

\author{
A. K. Sah ${ }^{1 *}$, R. Bastola ${ }^{2}$, Y. R. Pandeya ${ }^{1}$, L. Pathak ${ }^{1}$ M. P. Acharya ${ }^{1}$, D. R. Khanal ${ }^{3}$ \\ ${ }^{1}$ National Cattle Research Program, Nepal Agricultural Research Council, Chitwan \\ ${ }^{2}$ Animal Nutrition Division, Nepal Agricultural Research Council, Lalitpur \\ ${ }^{3}$ Animal Health Research Division, Nepal Agricultural Research Council, Lalitpur
}

(*email: anjay_sah@yahoo.com)

\begin{abstract}
Present study was carried out for the accuracy of commercially available progesterone ELISA kit at NCRP farm in the fiscal year 2015/16. Twenty crossbred Jersey and Holstein dairy cows were selected at different time periods of post insemination. Blood serum was collected in those animals and progesterone was quantified with the commercially available progesterone ELISA kit. Pregnancy diagnosis was performed by rectal palpation and Ultrasonography (USG) as a Gold standard and compared for the accuracy to ELISA kit. Results of the ELISA kit revealed the accuracy of the kit to be only $80 \%$ with high sensitivity $92 \%$ and very low specificity $57 \%$ at $95 \%$ confidence interval. Out of twenty artificially inseminated cows, thirteen were pregnant and seven were non-pregnant by the Gold standard test with their significantly different mean progesterone (at $P<0.05$ ) $8.93 \pm 1.10 \mathrm{ng} / \mathrm{ml}$ and $4.36 \pm 1.21 \mathrm{ng} / \mathrm{ml}$ respectively. Hence, it can be used in the early pregnancy diagnosis at only after 24 days of the insemination, however, progesterone quantification by ELISA is not the confirmatory tests for the pregnancy diagnosis as this results accuracy of only $80 \%$.
\end{abstract}

Keywords: sensitivity, specificity, pregnant, true positive, false positive

\section{INTRODUCTION}

Progesterone is the most biologically active progestogen in cattle and is primarily produced and secreted by the corpus luteum (CL) during estrous cycle and by both placenta and CL during pregnancy. Quantification of progesterone in blood or milk can be achieved in a laboratory using Radioimmunoassay (RIA) or Enzyme-Linked Immuno-Sorbent Assay (ELISA) methods. The biology of early pregnancy and maintenance of the CL results in distinct progesterone profiles for pregnant compared with non-pregnant cows. Hence, progesterone quantification could be helpful in pregnancy examination that could be diagnosed as early as 21-day post insemination (Fricke et al., 2016).

Pregnancy diagnosis is an important part of reproductive management to maintain the reproductive efficiency of the herds. In general, Nepalese dairy farms must wait more than a month to know the pregnancy status by rectal palpation and since, only the expert and trained skilled person can detect the pregnancy within that period by rectal examination; it may not be always accurate. Ultrasonography (USG) which gives almost $100 \%$ accuracy in the pregnancy confirmation is also not used in Nepal because it is expensive and needs well trained and skilled person for the examination (NCRP, Annual Report, 2016). 
Progesterone estimation by the commercially available kits is an important tool for early detection of pregnant animals. Cows can be diagnosed as early as 24 days after insemination. Progesterone analysis may be performed on the farm or in a veterinary clinic, but users must become familiar with the procedures, proper interpretation of results, and limitations of this tool (Pen State University, 2016).

Hence, there is clearly a potential in many dairy production systems of Nepal to apply this method as a diagnostic service to farmers. Therefore, the objective of this study was to verify the accuracy of these kits by progesterone estimation for the pregnancy diagnosis test in context to dairy cows of Nepal. Although the kits have several advantages like to carry out the test by milk samples, furnish the results by color changes in a micro-plate well and semi quantitative test, this study is confined in the analysis of the quantitative results only.

\section{MATERIALS AND METHODS}

Total 20 dairy cows with no uterine and ovarian pathology at the National Cattle Research Program (NCRP), Rampur, Chitwan were taken under the study. Four blood serum samples of within 37 to 40 days and rest samples beyond 45 -day post insemination were taken and stored at $-20^{\circ} \mathrm{C}$ before carrying out the progesterone estimation test at the Animal Health Research Division, Khumaltar, Lalitpur. Commercially available progesterone ELISA kit from the Abraxis LCC USA Company was used. Standard curve and average progesterone level $(\mathrm{ng} / \mathrm{ml})$ of high control were quantified from the ELISA optical density (OD) readings and its spreadsheet Excel calculation was identified as a cut-off point to differentiate positive and negative pregnancy. Mean \pm SEM of progesterone concentration $(\mathrm{ng} / \mathrm{ml})$ of the pregnant and non-pregnant cows were obtained and compared with ttest by using SPSS version 16. True positive, true negative, false positive and false negative count were used for the calculation of the sensitivity and specificity and finally, accuracy of the test at 95 $\%$ Confidence Interval (CI) was done from the calculator or programme written by Hutchon (2016). Transrectal palpation after two-month post AI as the Gold Standard test for the pregnancy diagnosis was also included and confirmation by B-mode Ultrasound Machine of $7.5 \mathrm{MHz}$ was followed which was assumed to be 100 percent accurate.

\section{RESULTS AND DISCUSSION}

\section{Standard Curve for the kit readings OD Values against progesterone quantification}

Four-parametric logistic fitting standard curve for the progesterone ELISA (Duplicates) obtained from those sample tests is given below in the Fig. 1. Average progesterone level of high control for micro plate well was quantified as $4.156 \mathrm{ng} / \mathrm{ml}$ and the concentration above this value was considered as pregnancy positive for every sample and the below as negative. 


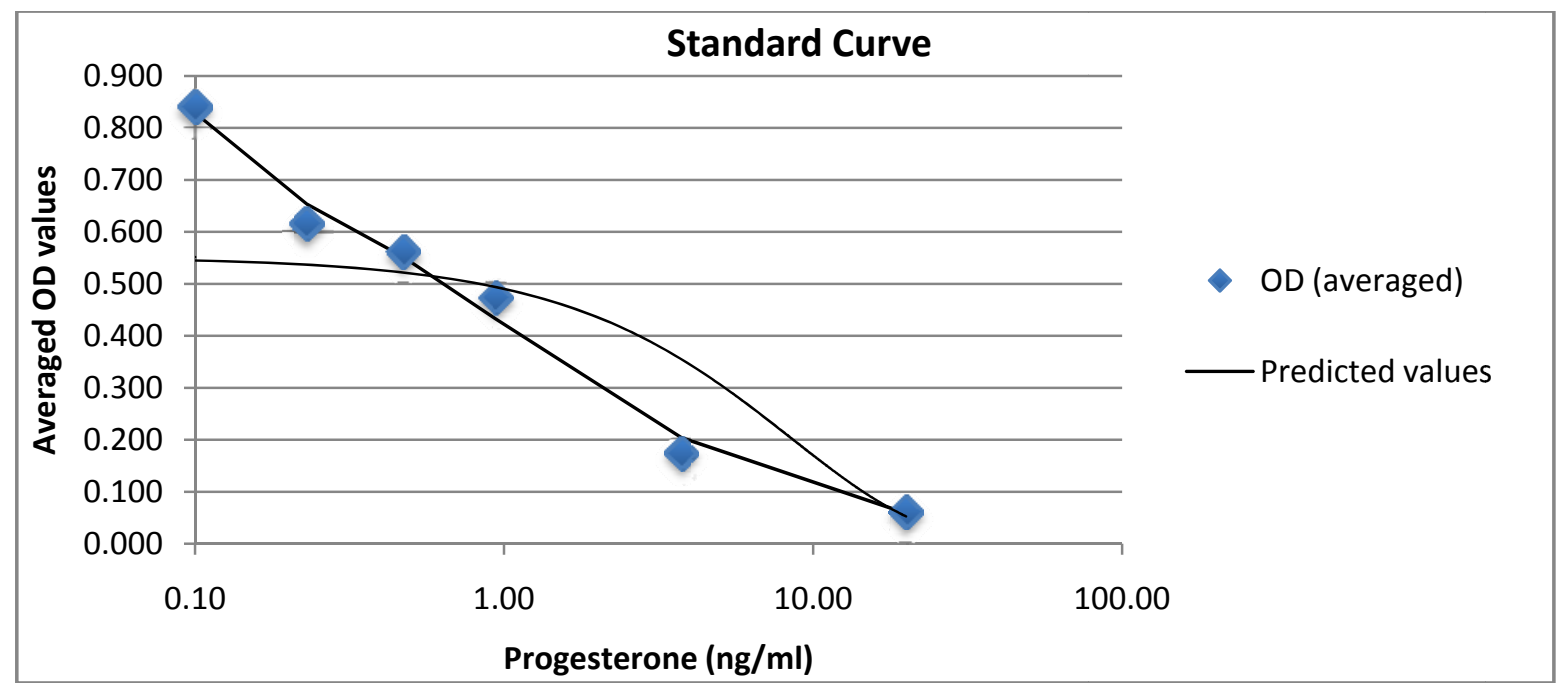

Fig. 1: Four-parametric logistic fitting standard curve for the progesterone ELISA

\section{Progesterone concentration of the pregnant cows}

Mean progesterone concentration in the Gold standard pregnant positive cows was found to be significantly different at $\mathrm{P}<0.05$ with $8.93 \pm 1.10 \mathrm{ng} / \mathrm{ml}$ in positive cows in comparison to negative cows (Table 1) which is consistence as reported by Gumen et al, 2003. However, the mean of the progesterone in negative cows was found to be more than individual set cut off point as calculated from kits for the average high control. This may be due to false positive results generated from the kit or luteul phase effect.

Table 1: Progesterone concentration in pregnant and non-pregnant cows

\begin{tabular}{lll}
\hline Pregnancy Status & Individual (n) & Mean \pm SEM (ng/ml) \\
\hline Positive & 13 & $8.93 \pm 1.10$ \\
Negative & 7 & $4.36 \pm 1.21$ \\
\hline
\end{tabular}

Mean \pm SEM (ng/ml) significantly different at $\mathrm{P}<0.05$

Sensitivity, specificity and accuracy of the progesterone test kit

Out of 15 tests positive as detected by the kit, 12 were detected as true positive against the 13 positive Gold Standard Test with 3 false positive having the sensitivity of $92 \%$ at $95 \% \mathrm{CI}$. Similarly, out of 5-test negative detected against 7 negative Gold Standard test, 4 were true negative and 1 false negative having the specificity $57 \%$ at $95 \%$ CI (fig. 2). And the accuracy of the kit results was only $80 \%$. 
Sensitivity and Specificity of the progesterone ELISA kits for the pregnancy diagnosis

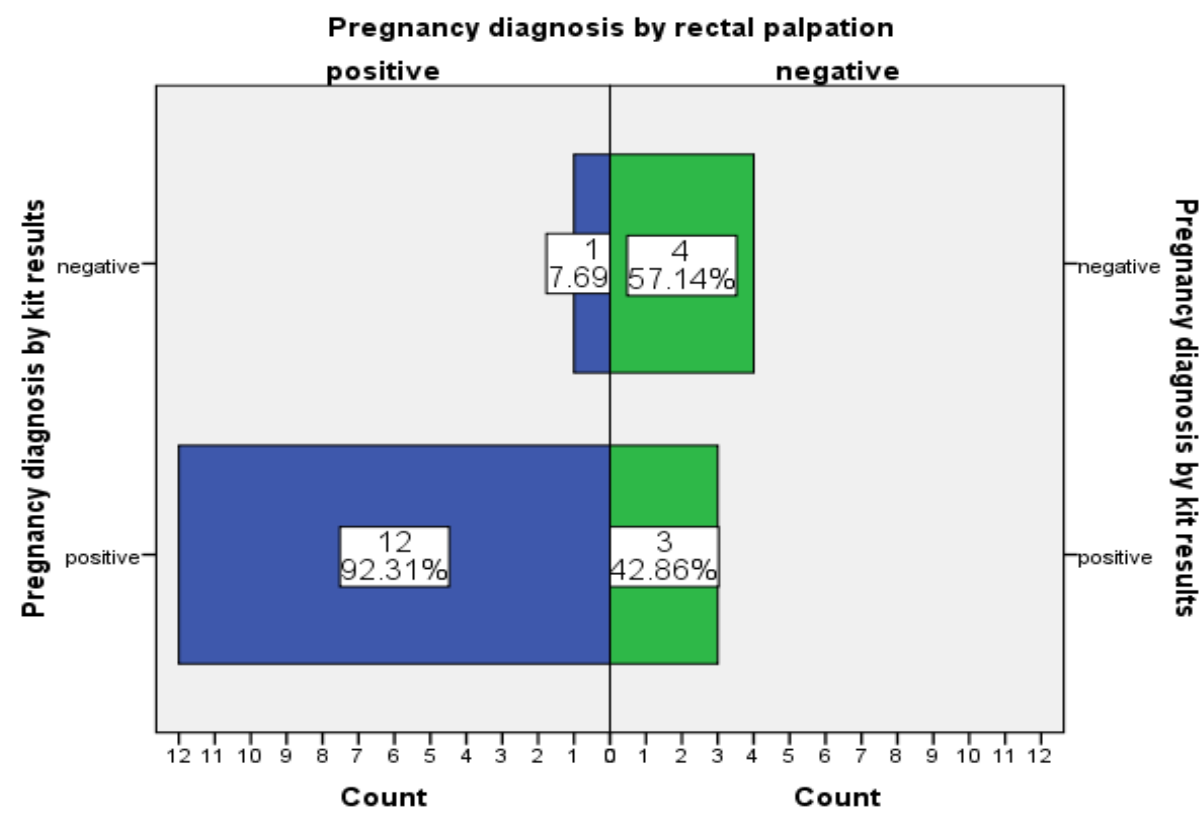

Fig. 2: Graph representing the ELISA kits test results against the Gold Standard Test Rectal palpation

Accuracy of pregnancy diagnosis was found to be $84 \%$ at an early stage $37-41$ day (Alam and Ghosh, 1994) which contrasts with this present study (Table 2) and $100 \%$ as reported by (Muhummad et al., 2000) which is similar to this study.

Table 2: ELISA Kits Pregnancy diagnosis results of the cows against Rectal Palpation Test at different stages of pregnancy

\begin{tabular}{|c|c|c|c|c|}
\hline \multicolumn{2}{|c|}{ Days Post Artificial Insemination } & \multicolumn{3}{|c|}{ Pregnancy Diagnosis by ELISA Kit test } \\
\hline & & $\begin{array}{l}\text { Positive Count } \\
\% \text { of Total }\end{array}$ & $\begin{array}{l}\text { Negative } \\
\text { Count } \\
\% \text { of Total }\end{array}$ & $\begin{array}{l}\text { Total Count } \\
\%\end{array}$ \\
\hline \multirow{6}{*}{$\begin{array}{l}\text { 37- } 45 \text { days pregnant } \\
\text { Pregnancy Diagnosis } \\
\text { by Rectal Palpation }\end{array}$} & Positive Count & 3 & & 3 \\
\hline & $\%$ of Total & $75.0 \%$ & 0 & $75.0 \%$ \\
\hline & Negative Count & 1 & 0 & 1 \\
\hline & $\%$ of Total & $25.0 \%$ & & $25.0 \%$ \\
\hline & Total Count \% & 4 & 0 & 4 \\
\hline & & $100.0 \%$ & & $100.0 \%$ \\
\hline \multirow{4}{*}{$\begin{array}{l}\text { 46- } 60 \text { days } \\
\text { Pregnancy Diagnosis } \\
\text { by Rectal Palpation }\end{array}$} & Positive Count & 2 & 1 & 3 \\
\hline & $\%$ of Total & $66.7 \%$ & $33.3 \%$ & $100.0 \%$ \\
\hline & $\begin{array}{l}\text { Negative Count } \\
\% \text { of Total }\end{array}$ & 0 & 0 & $0 \%$ \\
\hline & Total Count \% & 2 & 1 & 3 \\
\hline
\end{tabular}




\begin{tabular}{|c|c|c|c|c|}
\hline \multirow{7}{*}{$\begin{array}{l}\text { 61-90 days } \\
\text { Pregnancy Diagnosis } \\
\text { by Rectal Palpation }\end{array}$} & & $66.7 \%$ & $33.3 \%$ & $100.0 \%$ \\
\hline & Positive Count & 1 & 0 & 1 \\
\hline & $\%$ of Total & $33.3 \%$ & & $33.3 \%$ \\
\hline & Negative Count & 2 & 0 & 2 \\
\hline & $\%$ of Total & $66.7 \%$ & & $66.7 \%$ \\
\hline & Total Count \% & 3 & 0 & 3 \\
\hline & & $100.0 \%$ & & $100.0 \%$ \\
\hline \multirow{6}{*}{$\begin{array}{l}91-120 \text { days } \\
\text { Pregnancy Diagnosis } \\
\text { by Rectal Palpation }\end{array}$} & Positive Count & 0 & 0 & 0 \\
\hline & $\%$ of Total & & & \\
\hline & Negative Count & 0 & 2 & 2 \\
\hline & $\%$ of Total & & $100.0 \%$ & $100.0 \%$ \\
\hline & Total Count & 0 & 2 & 2 \\
\hline & $\%$ of Total & & $100.0 \%$ & $100.0 \%$ \\
\hline \multirow{6}{*}{$\begin{array}{l}\text { beyond } 120 \text { days } \\
\text { Pregnancy Diagnosis } \\
\text { by Rectal Palpation }\end{array}$} & Positive Count & 6 & 0 & 6 \\
\hline & $\%$ of Total & $75.0 \%$ & $0.0 \%$ & $75.0 \%$ \\
\hline & Negative Count & 0 & 2 & 2 \\
\hline & $\%$ of Total & $0.0 \%$ & $25.0 \%$ & $25.0 \%$ \\
\hline & Total Count & 6 & 2 & 8 \\
\hline & $\%$ of Total & $75.0 \%$ & $25.0 \%$ & $100.0 \%$ \\
\hline
\end{tabular}

Similarly, there was non-significant results on the accuracy of diagnosis upon parity basis as reported by (Muhummad et al, 2000) which is as similar to this study results (Table 3).

Table 3: Pregnancy diagnosis by the ELISA kit results against Rectal Palpation test in cows at different parity

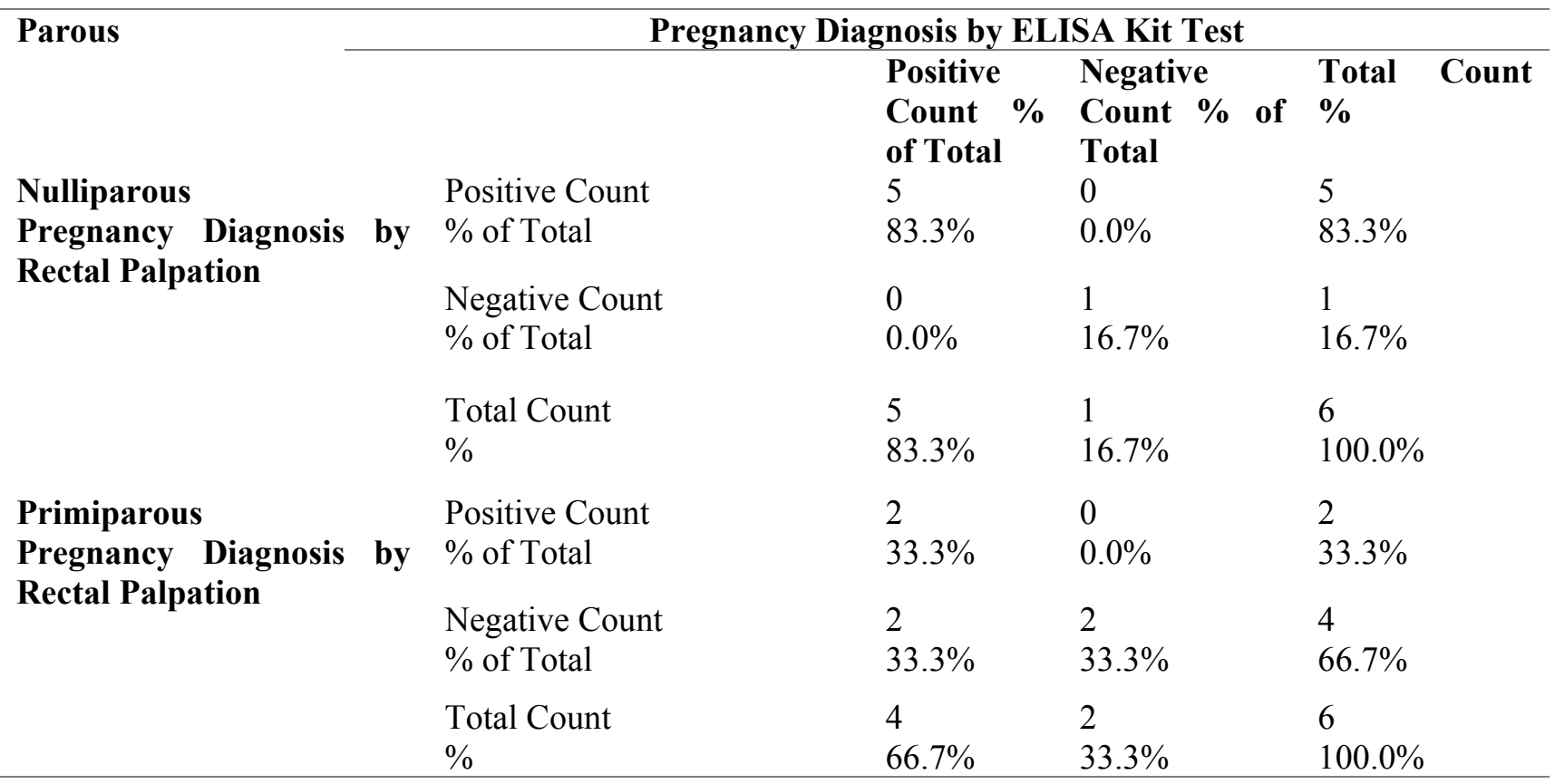




\begin{tabular}{|c|c|c|c|c|}
\hline \multirow{4}{*}{$\begin{array}{l}\text { Pluriparous } \\
\text { Pregnancy Diagnosis by } \\
\text { Rectal Palpation }\end{array}$} & Positive Count & 5 & 1 & 6 \\
\hline & $\%$ of Total & $62.5 \%$ & $12.5 \%$ & $75.0 \%$ \\
\hline & Negative Count & $\begin{array}{l}1 \\
12.5 \%\end{array}$ & $\begin{array}{l}1 \\
125 \%\end{array}$ & $\begin{array}{l}2 \\
250 \%\end{array}$ \\
\hline & $\begin{array}{l}\text { Total Count } \\
\%\end{array}$ & $\begin{array}{l}6 \\
75.0 \%\end{array}$ & $\begin{array}{l}2 \\
25.0 \%\end{array}$ & $\begin{array}{l}8 \\
100.0 \%\end{array}$ \\
\hline
\end{tabular}

Several studies in the U.S. and Europe have evaluated milk progesterone analysis as a method of pregnancy diagnosis. Generally, it has been shown that high progesterone in 20 to 24 days postbreeding is only 75 percent accurate in confirming pregnancy. There are various conditions such as severe uterine infection, some cystic ovarian conditions and early embryonic death other than pregnancy can cause high progesterone concentrations 20 to 23 days' post breeding (Penn State University, 2016).

\section{CONCLUSION}

It can be said that progesterone quantification by EIA is not the confirmatory tests for the pregnancy diagnosis as this also gives the false positive and false negative results with the accuracy of only $80 \%$ however, it can be used in the early pregnancy diagnosis as a screening purpose after 21 to 24 days of insemination as this can almost predict the positive pregnant animals as a positive with high sensitivity.

\section{ACKNOWLEDGEMENT}

Nepal Agricultural Research Council for accepting the proposal and its implementation through National Cattle Research Programme.

\section{REFERENCES}

Alam and Ghosh. (1994). Plasma and milk progesterone concentrations and early pregnancy in Zebus. AJAS 1994 Vol 7(1): 131-136.

Annual Report. (2016). National Cattle Research Program, Rampur, Chitwan. Nepal Agricultural Council. 2016.

Fricke, Paul M., Ricci, A., Julio O. Giordano and Paulo D. Carvalho. (2016). Methods for and Implementation of Pregnancy Diagnosis in Dairy Cows. Article inVeterinary Clinics of North America Food Animal Practice, February 2016. Retreived fromhttps://www.researchgate.net/publication.

Gumen A, Guenther J.N. and Wiltbank M.C. (2003). Follicular size and response to Ovsynch versus detection of estrus in anovular and ovular lactating dairy cows. J Dairy Sci 2003;86:3184-3194.

Muhummad, F., Sarwar, A., Hayat C.S. and Anwar M.I. (2000). Peripheral plasma progesterone concentration during early pregnancy in Holstein Friesian cows. Pakistan Vet. J.20(4):2000

Pen State University. (2016). Pen State Extension. Milk Progesterone Analysis for Determining Reproductive Status. Retrieved from http://extension.psu.edu. 